\section{Commentary: What's in the secret sauce? With so many ingredients, who knows...but maybe, who cares?}

\author{
Priscilla Yu, MD, and Joshua S. Wolovits, MD
}

Neonates with single-ventricle physiology are at the greatest risk of acute deterioration and death of all children with congenital heart disease. Factors including volume overload, circulatory imbalance, and risk of shunt thrombosis ${ }^{1}$ make these patients particularly vulnerable. Results from the Single Ventricle Reconstruction Trial demonstrated that nearly $18 \%$ of deaths were sudden and unexpected ${ }^{2}$ during hospitalization for stage I palliation. Although seemingly unpredictable, early warning tools have the potential to reduce such events. Recent efforts such as the Pediatric Cardiac Critical Care Consortium (PC4) Cardiac Arrest Prevention trial have aimed to reduce cardiac arrest in high-risk patients. Unpublished results from this trial involving implementation of a cardiac arrest prevention "bundle" appear promising. However, sustainability has not been demonstrated following study closure. Might patient-specific, real-time data prevention strategies be more effective?

In this issue of the Journal, Ruiz and colleagues ${ }^{3}$ tap into the data-rich electronic health record (EHR) to explore its potential to recognize deterioration using a machinelearning model. At its core, the notion is very attractive: use available data, rather than add new and expensive technology, such as advanced monitoring systems, which continue to grow in popularity and cost. While other groups have published their work in creating models to detect the risk of deterioration in children with heart disease, ${ }^{4-6}$ these models have relied on the use of high-frequency continuous physiologic data. The idea of using discrete,

\footnotetext{
From the Division of Critical Care Medicine, Department of Pediatrics, UT Southwestern Medical Center; and Children's Medical Center, Dallas, Tex.

Disclosures: The authors reported no conflicts of interest.

The Journal policy requires editors and reviewers to disclose conflicts of interest and to decline handling or reviewing manuscripts for which they may have a conflict of interest. The editors and reviewers of this article have no conflicts of interest.

Received for publication Nov 10, 2021; revisions received Nov 10, 2021; accepted for publication Nov 23, 2021; available ahead of print Nov 29, 2021.

Address for reprints: Joshua S. Wolovits, MD, Division of Critical Care Medicine, Department of Pediatrics, UT Southwestern Medical Center, 1935 Medical District Dr, Dallas, TX 75235 (E-mail: Joshua.Wolovits@UTSouthwestern.edu).

J Thorac Cardiovasc Surg 2022;164:223-4

$0022-5223 / \$ 36.00$

Copyright (c) 2021 by The American Association for Thoracic Surgery https://doi.org/10.1016/j.jtcvs.2021.11.061
}
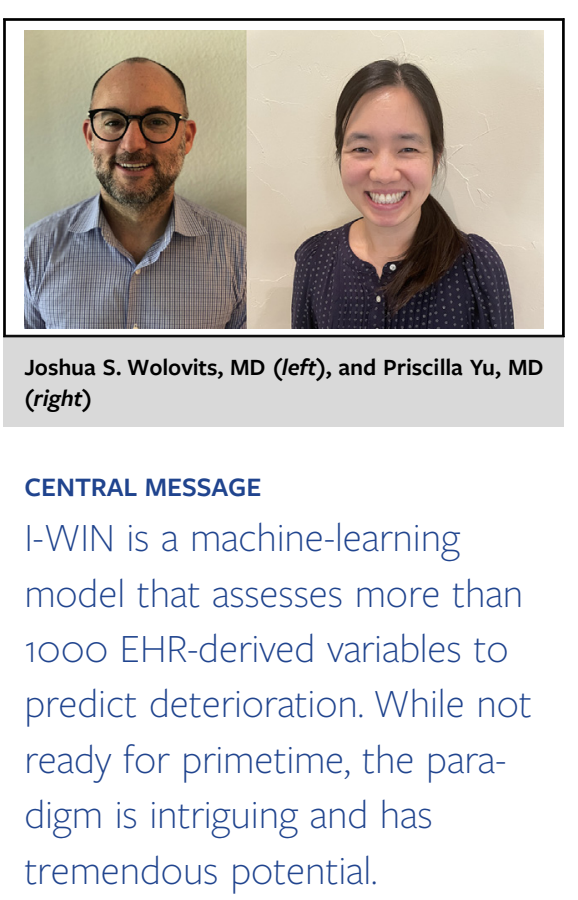

rather high-fidelity and waveform data is very provocative. Perhaps the high-fidelity waveform data are the trees, but do not tell us as much as we would like about the forest?

The Intensive care Warning Index (ie, I-WIN) assessed more than 1000 EHR-derived variables to predict deterioration. The model appears to be robust and predicts potential events far in advance with good receiver operating characteristics starting at 8 hours before an event. This lead time could allow ample time for the clinician to investigate, manage, and avoid further decompensation. However, with so many variables, how does a clinician respond to such a warning? An "ideal" prediction model would alert a clinician that the patient is at high risk of deterioration and help the clinician understand why. In physiologybased early warning systems and predictive analytics, such Etiometry's T3 IDO2 index, input variables are known, allowing some insight into what is driving the warning signal. Although the authors do list the top 10 most influential features of their model, what about the other $990+$ variables? Are they the secret to the sauce or just thrown into the pot to dazzle and distract the customer from a more simple and humble meal?

This model was tested on a very homogenous, high-risk group of patients. A typical pediatric cardiac intensive care unit is filled with many other patients at high risk for deterioration, such as patients with acute decompensated heart failure from myocarditis. Can this model be applied 
to such patient populations? Does the secret sauce go with any meal? And while we want to know what's in the secret sauce, the data are compelling, so maybe it just does not matter. We look forward to seeing how this model performs in a prospective cohort to find out.

\section{References}

1. Marino BS, Tabbutt S, MacLaren G, Hazinski MF, Adatia I, Atkins DL, et al. Cardiopulmonary resuscitation in infants and children with cardiac disease: a scientific statement from the American Heart Association. Circulation. 2018;137:e691-782.

2. Ohye RG, Schonbeck JV, Eghtesady P, Laussen PC, Pizarro C, Shrader P, et al. Cause, timing, and location of death in the Single Ventricle Reconstruction trial. J Thorac Cardiovasc Surg. 2012;144:907-14.
3. Ruiz V, Goldsmith M, Shi L, Simpao A, Galvez J, Naim MY, et al. Early prediction of clinical deterioration using data-driven machine-learning modeling of electronic health records. J Thorac Cardiovasc Surg. 2022;164: 211-22.e3.

4. Rusin CG, Acosta SI, Vu EL, Ahmed M, Brady KM, Penny DJ. Automated prediction of cardiorespiratory deterioration in patients with single ventricle. $J \mathrm{Am}$ Coll Cardiol. 2021;77:3184-92.

5. Bose SN, Verigan A, Hanson J, Ahumada LM, Ghazarian SR, Goldenberg NA, et al. Early identification of impending cardiac arrest in neonates and infants in the cardiovascular ICU: a statistical modelling approach using physiologic monitoring data-CORRIGENDUM. Cardiol Young. 2019;29:1349.

6. Futterman C, Salvin JW, McManus M, Lowry AW, Baronov D, Almodovar MC, et al. Inadequate oxygen delivery index dose is associated with cardiac arrest risk in neonates following cardiopulmonary bypass surgery. Resuscitation. 2019:142:74-80
See Article page 211.

\section{Commentary: In analytics}

we trust?

\author{
John D. Cleveland, MD, and \\ S. Ram Kumar, MD, PhD, FACS
}

Tampa Bay Rays' left-handed pitcher Blake Snell was arguably having his best outing of the year during game 6 of the 2020 World Series. He had pitched 5-1/3 scoreless innings and recorded 9 strikeouts. To the dismay of many, the Rays' manager replaced Snell to avoid him from facing the Los Angeles Dodgers batting order for a third time (a statistical advantage for batters ${ }^{1}$ ). His replacement immediately gave up 2 runs and the championship to the Dodgers. ${ }^{2}$ Fans and players alike were left questioning the manager's decision, wondering what could have happened. Stories like this are common in modern Major League Baseball as teams have become heavily reliant on statistics to make in-game decisions. When such decisions fail, we are left to ponder how

From the Division of Cardiac Surgery, Department of Surgery, Keck School of Medicine of the University of Southern California; and Heart Institute, Children's Hospital Los Angeles, Los Angeles, Calif.

Disclosures: The authors reported no conflicts of interest.

The Journal policy requires editors and reviewers to disclose conflicts of interest and to decline handling or reviewing manuscripts for which they may have a conflict of interest. The editors and reviewers of this article have no conflicts of interest.

Received for publication Nov 27, 2021; revisions received Nov 27, 2021; accepted for publication Nov 30, 2021; available ahead of print Dec 3, 2021.

Address for reprints: S. Ram Kumar, MD, PhD, FACS, Children's Hospital, Los Angeles, 4650 Sunset Blvd, Mailstop \#66, Los Angeles, CA 90027 (E-mail: rsubramanyan@surgery.usc.edu).

J Thorac Cardiovasc Surg 2022;164:224-6

$0022-5223 / \$ 36.00$

Copyright (c) 2021 by The American Association for Thoracic Surgery

https://doi.org/10.1016/j.jtcvs.2021.11.075
Check for updates

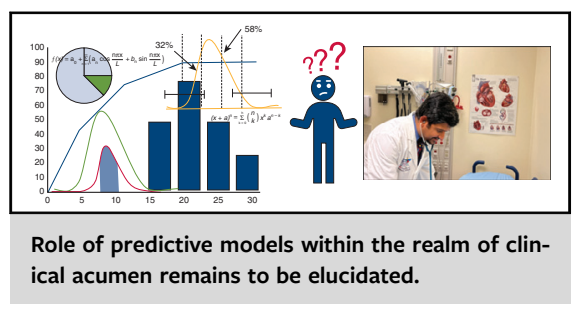

CENTRAL MESSAGE

Predictive analytics could play a

supportive role in the care of sick

infants with complex congenital

heart disease when used in

conjunction with sound clinical

judgment. well algorithms can predict complex outcomes and how heavily one should incorporate statistics into the next decision.

Identifying patients at risk for clinical deterioration in the postoperative period following surgery for congenital heart defects (CHD) continues to be a sought after, yet evasive, goal. Just like in baseball, a plethora of complex machinelearning statistical models has been proposed to accurately predict adverse outcomes in the pediatric cardiac intensive care unit (ICU). ${ }^{3}$ Some of these models rely primarily on continuously collected physiologic variables, such as the $\mathrm{IDO}_{2}$ (inadequate oxygen delivery) index. ${ }^{4}$ Others, such as the Pediatric Index of Cardiac Surgical Intensive Care 